\title{
Psychiatric Emergencies in a Tertiary Care Hospital
}

\author{
Shakya DR, Shyangwa P M, Shakya R. \\ Department of Psychiatry, B P Koirala Institute of Health Sciences, Dharan, Nepal.
}

\section{ABSTRACT}

People with psychiatric problems often visit a general hospital. Many of them require emergency service. B P Koirala Institute of Health Sciences (BPKIHS) is one of the few health institutes in Nepal providing comprehensive 24-hour psychiatric emergency service. This study aims to document the pattern of psychiatric emergencies in a tertiary care hospital of Eastern Nepal.

All psychiatric emergencies referred from different departments in 30 random days during a sixmonth period were enrolled. This is a descriptive study with convenience sampling method where the diagnoses were made based on the'International Classification of Disease and Infirmity' (ICD10).

One hundred twenty-nine cases were referred in the study period. The M:F ratio was 1.3:1. The service users were predominantly young adults. The majority of cases were seen in the emergency department and medical ward. The most common causes for the consultation were behavioral problems (39\%), altered consciousness (32\%) and somatic complaints (17\%). Approximately 83\% received the diagnosis of Category F of the ICD-10. Mental and behavioral disorder due to substance use (F10-19) was the most common disorder (30\%), followed by mood/affective disorders (23\%) and neurotic, stress-related anxiety disorders (16\%). Roughly $46 \%$ had co-morbid physical illnesses and $8 \%$ received only a physical diagnosis. About $20 \%$ had attempted suicide using different means, poisoning being the most common.

Emergency psychiatric consultation for mental problems is sought by almost all departments of a general hospital. These consultations are most commonly sought for substance use, mood or anxiety disorders.

Key Words: Behavioral problems, psychiatric emergency, psychiatric disorders, substance abuse.

\author{
Correspondence: \\ Dr. Dhana Ratna Shakya \\ Department of Psychiatry, B P Koirala Institute of Health \\ Sciences, Dharan, Nepal. \\ E-mail: drdhanashakya@yahoo.com
}


Shakya et al. Psychiatric Emergencies in a Tertiary Care Hospital

\section{INTRODUCTION}

Emergency service is a vital component of and is the gateway to different departments of a general hospital facility. ${ }^{1}$ A significant proportion of people with mental and behavioral problems visit the hospital on an emergency basis. Likewise, the people presenting with physical illness frequently have a concurrent psychiatric problem or may develop it subsequently. American data show a rapid increase in the rate of psychiatric patient emergency visits in the last decades after the de-institutionalization movement. ${ }^{2}$ A similar trend may be witnessed by Nepalese hospitals with the rise in public awareness of mental illness in future. To provide service to the people in psychological crisis, a 24-hour emergency psychiatry service is as important as any other specialty.

Psychiatric emergency is an acute disturbance of thought, mood, behavior and social relationship that requires an immediate intervention as defined by patient, family or the community. ${ }^{3}$ In case the required attention is not given, it may endanger patients, someone close to them and/or the surrounding or property. Therefore, psychiatric emergency requires immediate attention as well as prompt and decisive intervention.

There are a few institutes providing comprehensive psychiatric emergency services in Nepal, namely Tribhuvan University Teaching hospital, Maharajgunj, in Kathmandu Valley and BPKIHS in Dharan. Some other health institutes also provide this service. In BPKIHS, the department of psychiatry provides 24-hour emergency service manned with on-duty resident and on-call consultant. This descriptive study of psychiatric emergency service analyzed the pattern of presentation of psychiatric cases.

Despite all of the progress in mental health services, emergency psychiatry has received little attention in our country. But, the growing need for the psychiatric emergency is becoming obvious. In Western settings, the majority of the emergency psychiatric care is rendered in the emergency department of the general medical hospitals and crisis units of the community mental hospital care. ${ }^{4}$ The main users of this service are single, divorced or widowed. Young adults (25-44 years) present most frequently with psychiatric disorders, women predominantly with depressive episodes and phobias, and men anti-social personality problems and alcohol-use problems. ${ }^{4}$ The most commonly encountered diagnoses in psychiatric emergency are affective disorders, substance-use disorders and antisocial personality disorders. ${ }^{5}$ The presence of significant medical and substance-abuse co-morbidity complicates emergency decision-making, and requires expanding knowledge of differential diagnoses and therapeutic techniques. A study conducted in a Western country shows that nearly half $(46 \%)$ were found to have medical illness that either exacerbated or triggered their psychiatric illnesses, most of them requiring treatment. ${ }^{6}$ The admission rate for people seen in the emergency for psychiatric reasons is more than twice that of people who visit it for physical problems, roughly $12 \%$ for physical reasons. ${ }^{3}$

In the Nepalese context, there is a dearth of study and data on psychiatric emergency. Though there have been some studies on consultation liaison psychiatry, ${ }^{7,8,9}$ of which emergency psychiatry is a part, few have intensively looked at the psychiatric emergencies. ${ }^{10}$ The need, the effectiveness and the areas of preparation for this service may still be the matter of discussion in our context despite its clear indication in literature. Systematic data is expected to draw the attention of administrators, policy makers and all others concerned. The present study, therefore, was conducted to explore about psychiatric emergencies in a tertiary care hospital in eastern Nepal.

\section{MATERIALS \& METHODS}

\section{Subjects}

The subjects for this study consisted of all patients seeking emergency psychiatric consultation in BPKIHS, Dharan, in 30 random days over a six-month period $(2005 / 6)$. The days were randomly allotted among all the residents by the department as per duty schedule and the investigator collected the information from all the psychiatric emergency cases of those assigned days. The consent was obtained after a brief explanation about the study from the subjects and the family members attending the patient at the time of consultation. The information was kept confidential. Patients not giving consent, seen in non-emergency or out-patient routine or follow-up basis were excluded.

The socio-demographic profile and information about the illness (reason for referral, referring unit/department, physical diagnosis, co-morbid conditions, psychiatric diagnosis) were recorded during a detailed psychiatric assessment and necessary investigative procedures. The final psychiatric diagnosis was made according to the $10^{\text {th }}$ edition of 'International Classification of Disease and Infirmity' (ICD-10). ${ }^{11}$ The data was analyzed using 'Statistical Package for the Social Science' (SPSS) software.

\section{RESULTS}

One hundred and twenty-nine patients fulfilled the criteria of inclusion. Out of 129 psychiatric emergency patients, $73(56.5 \%)$ were male and 56 (43.5\%) female with a M:F ratio of $1.3: 1$, showing slight male 
preponderance. Patients of age group 20-29 years constituted the largest proportion, $31 \%(n=40)$, followed by $30-39$ years age group, $23.3 \%(n=30)$, and $40-49$ years age group, $17 \%(n=22)$ (Figure 1$)$. Table 1 depicts the ethnicity distribution of the subjects. The major ethnic groups of this study are - Brahmin 31 (24\%), the people of Terai origin 30 (23.25\%), Rai/ Limbu 23 (18\%).

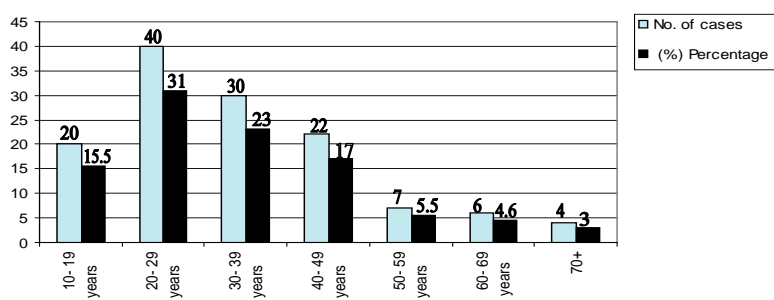

Figure1. Age distribution

The largest number of psychiatric emergency cases came from the department of emergency and family medicine, $67(52 \%)$, followed by medical ward 34, $(26 \%)$ and surgical ward $11(8.5 \%)$ (Table 2). The most common reasons for the emergency psychiatric consultation were behavioral problems 50 (39\%), altered consciousness 41 (31.9\%) and physical/somatic complaints 23 (18\%). Among the 129 patients, 107 $(83 \%)$ received the diagnosis of category- $F$, Mental and Behavioral disorders of ICD-10. The commonest psychiatric diagnosis was substance-use disorders, $38(30 \%)$, followed by mood (affective) disorders, $30(23 \%)$. Ten cases had more than one psychiatric diagnosis. Forty-six percent of the cases had concurrent physical diseases. Among them, most had diseases of nervous system and gastro-intestinal system (Table 3a, 3b).

Table1. Demographic profile of the study population

\begin{tabular}{lcc}
\hline Ethnic group & Frequency & Percentage \\
\hline Brahmins & 31 & 24.0 \\
Terai origin & 30 & 23.2 \\
Rai/Limbu & 23 & 18.0 \\
Chhetri & 20 & 15.5 \\
Disadvantaged group & 9 & 6.9 \\
Newar & 4 & 3.1 \\
Magar & 4 & 3.1 \\
Tamang & 4 & 3.1 \\
Sherpa/Gurung & 4 & 3.1 \\
\hline
\end{tabular}

About $22 \%$ of cases were brought for intentional selfharm. Among them, nearly $65 \%$ were found to have been suffering from mental illness. The commonest mode of intentional self-harm was poisoning by organophosphorous or other compound $\{19(68 \%)$ of 28 cases\} (Figure 2).

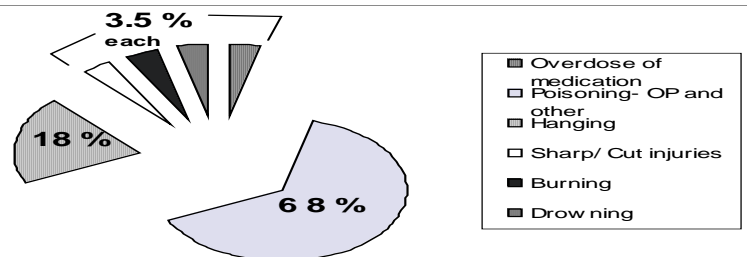

Figure 2: Methods of self harm

Table 2. Referring departments in order of frequency

\begin{tabular}{lcc}
\hline Departments & Frequency & Percent \\
\hline Emergency & 67 & 51.7 \\
Medicine & 34 & 26.3 \\
Surgery & 11 & 8.5 \\
Gynaecology/Obstetric & 5 & 3.9 \\
ICU/CCU & 3 & 2.3 \\
Pediatrics & 2 & 1.7 \\
Dermatology & 2 & 1.7 \\
Orthopedics & 1 & 0.8 \\
ENT & 1 & 0.8 \\
Others & 3 & 2.3 \\
Total & 129 & 100.0 \\
\hline
\end{tabular}

Table3a. Presenting complaints of the patients

\begin{tabular}{lcc}
\hline \multicolumn{1}{c}{ Complaints } & Frequency & $\begin{array}{c}\text { (\%) of total } \\
\text { cases }\end{array}$ \\
\hline Disturbed behavior & 50 & 39.0 \\
Altered consciousness & 41 & 31.9 \\
Harming self/others & 28 & 21.7 \\
$\begin{array}{l}\text { Physical/Somatic } \\
\text { complaints }\end{array}$ & 23 & 18.0 \\
Mood symptoms & 13 & 10.1 \\
Anxiety & 7 & 5.4 \\
Substance abuse & 3 & 2.3 \\
\hline
\end{tabular}


Shakya et al. Psychiatric Emergencies in a Tertiary Care Hospital

Table 3b. Psychiatric diagnosis and co-morbid conditions of the study population

\begin{tabular}{|c|c|c|}
\hline Psychiatric diagnosis & Frequency & Percent \\
\hline Organic mental (F00-09) & 15 & 11.6 \\
\hline Substance use (F10-19) & 38 & 29.5 \\
\hline $\begin{array}{l}\text { Schizophrenia \& related (F20- } \\
\text { 29) }\end{array}$ & 13 & 10.1 \\
\hline Mood/affective (F30-39) & 30 & 23.3 \\
\hline $\begin{array}{l}\text { Neurotic, stress related, } \\
\text { anxiety (F31-39) }\end{array}$ & 20 & 15.5 \\
\hline Physiological (F40-49) & 1 & 0.8 \\
\hline Deliberate Self harm/Suicidal & 28 & 21.7 \\
\hline No psychiatric diagnosis & 22 & 17.1 \\
\hline \multicolumn{3}{|l|}{ Co-morbid conditions } \\
\hline Central Nervous system & 13 & 10.1 \\
\hline Digestive system & 11 & 8.5 \\
\hline Metabolic/endocrine & 7 & 5.4 \\
\hline Cardio-vascular system & 7 & 5.4 \\
\hline Skin/musculo-skeletal & 6 & 4.8 \\
\hline Congenital abnormality & 5 & 3.9 \\
\hline Infection/malignancy & 5 & 3.9 \\
\hline Respiratory system & 3 & 2.3 \\
\hline Gynae/obstetrical & 2 & 1.7 \\
\hline
\end{tabular}

Table 4. Management of the patients

\begin{tabular}{lcc}
\hline Treatment modality & $\begin{array}{c}\text { No. of } \\
\text { cases }\end{array}$ & $\begin{array}{c}\text { (\%) } \\
\text { Percent }\end{array}$ \\
\hline Benzodiazepines & 91 & 70.5 \\
Antipsychotic & 44 & 34.1 \\
\hline Supplementation & 28 & 21.7 \\
\hline Admission in Psych ward & 27 & 20.9 \\
\hline Antidepressant & 21 & 16.3 \\
\hline Counseling/psych ed. & 14 & 10.9 \\
\hline Other/IV fluids & 12 & 9.3 \\
\hline Mood stabilizer & 11 & 8.5 \\
\hline Symptomatic/analgesic & 2 & 1.5 \\
\hline Restraints & 1 & 0.8 \\
\hline ECT & 1 & 0.8 \\
\hline Referrals & 15 & 11.6 \\
\hline
\end{tabular}

The commonest treatment provided includes benzodiazepines followed by anti-psychotics. Twentyseven percent of patients required admission for further treatment. Fifty-five percent were called for subsequent therapy (Table 4). About $11 \%$ patients needed only counseling as treatment.

\section{DISCUSSION}

Emergency psychiatry service, a part of consultation liaison psychiatry, deserves due consideration because of its need for the prompt intervention, serious nature and magnitude of the problem. Though some studies have been carried out in psychiatric consultation liaison, ${ }^{7,8,9}$ to the best of our knowledge, there are few exclusive studies in Nepal on psychiatric emergencies. ${ }^{10}$ It is hoped that emergency psychiatry will receive due attention from all the concerned sides. And, this study highlights the need of and the areas of necessary preparedness for psychiatric emergency services.

Most of the patients (about 70\%) were of the age group 20-50 years, similar as in an American study. ${ }^{3}$ The ethnicity distribution of this study was, mainly, Brahmins, Terai origins, Rai and Limbu, more or less keeping with the population distribution of this region and their varying level of health awareness. Only 7\% were from the disadvantaged groups. This meager figure in utilizing available health services may indicate the degree of their backwardness; poverty and illiteracy.

The most common presenting complaints in psychiatric emergency consultation were disturbed behavior, altered consciousness and disorientation, neurovegitative (disturbance in sleep, appetite, libido, bowel and bladder habit) and somatic symptoms (medically unexplained bodily complaints), sadness or elation of mood, death wishes or suicidal tendencies. Some patients presented with drug adverse effects and their potential threat to others, i.e. violence. Most of the cases $(52 \%)$ were referred from the department of emergency and casualty. Nearly half came from other departments of the institute, mainly medical and surgical departments.

Eighty-three percentage subjects received the diagnosis of Category-F, Mental and Behavioral disorders of ICD-10 and $17 \%$ did not receive any psychiatric diagnosis. Among the recipients of psychiatric diagnosis, substance-use disorders was found to be the most common psychiatric diagnosis in emergency presentation, which reflects the magnitude and seriousness of the problem in this region. This finding replicates the very high prevalence of substance/ alcohol abuse $(26 \%)$ in the general population of this part. ${ }^{12}$ Apart from this high substance-abuse statistics, depressive illness (unipolar), bipolar affective disorders, 
anxiety, somatoform dissociative conversion disorders and a variety of psychotic disorders (including 'acute and transient psychotic disorders'- ATPD) are among the chief psychiatric conditions leading to emergency situations. The latter statistics is consistent with the findings of studies from other parts. 5,9,13 Many people presented with longstanding but less severe symptoms flared up during stress, in severe forms, like psychotic symptoms in depressive illness.

Deliberate self-harm has been found in $22 \%$ of the subjects, most of them consuming organo-phosphorous or other types of poisons. This reflects the easy availability of the poison. Among them, $65 \%$ carried one or more psychiatric diagnoses which is comparable to the findings in other parts of the world. ${ }^{4,14}$ Forty-six percent of the patients had general medical conditions with or without mental illness. This may be interpreted either as over-sensitivity or inadequate knowledge about mental illness in the non-psychiatric medical professionals. The most commonly affected organ systems were central nervous, digestive, metabolic and cardio-vascular system. About two-fifth of the cases had to be transferred to the psychiatric ward.
The commonest mode of management was medication, mainly benzodiazepines and anti-psychotics. The high use of benzodiazepine, being the main stay of the treatment of alcohol withdrawal, is in parallel with the high diagnostic statistics of the substance use disorder, particularly alcohol-related. We included the data collected in a hospital setting through convenience sampling method and there may be over-or-under representation of referrals from other departments due to different attitudes and level of knowledge; thus, the results of this study may not be generalized.

\section{CONCLUSIONS}

Emergency psychiatric consultation for mental problems is sought by almost all departments of a general hospital, most commonly for substance use and mood or anxiety disorders. Use of psychotropic drugs, mainly benzodiazepines, is the common mode of management of psychiatric conditions in emergency settings. Providing quality psychiatric emergency services is important in general hospitals.

\section{ACKNOWLEDGEMENT}

Prof. Dr. Sandra Connell, consultant psychiatrist and psychotherapist, University of Washington.

\section{REFERENCES}

1. Stefan S. Emergency Department Assessment of Psychiatric Patients: Reducing Inappropriate Inpatient Admissions. CME/CE. August 1, 2006. Available at www.medscape.com/viewprogram/5768. CME@ medscape.net or CME@webmd.net. (electronic media)

2. American College of Emergency Physicians. Emergency Departments See Dramatic Increase in People with Mental Illness - Emergency Physicians Cite State Health Care Budget Cuts as Root of Problem. April 27, 2004. Available at http://www. acep.org/webportal/Newsroom/NR/general/2004/ Emergency. (electronic media)

3. Allen MH, Forster P, Zealberg J, Currier G. American Psychiatric Association Task Force on Psychiatric Emergency Services: Report and Recommendations Regarding Psychiatric Emergency and Crisis Services. August 2002. Available at http://www.psych.org/ edu/other_res/lib_archives/archives/tfr/tfr200201. pdf. Accessed July 6, 2006. (electronic media)

4. Robins LN, Kulbok PA. Epidemiological studies in Suicide. Psychiatric Annals, 1988; 18: 619-27.

5. Robins E, Gentry KA, Munoz RA, Marten S. A contrast of the three more common illnesses with the ten less common in a study \& 18 month follow up of 314 psychiatric emergency room patients: I) characteristics of the sample and methods of study. II) Characteristics of patients with three more common illnesses. III) Findings at follow up. Arch Gen Psychiatry, 1977; 34: 185-291.

6. Hall RCW, Garden ER, Stichney SR et al. Physical illnesses manifesting as psychiatric illness: II. Analysis of a state hospital inpatient population. Arch Gen Psych, 1980; 37: 989-95.

7. Khalid A, Koirala NR, Regmi SK et al. A Prospective Study of Consultation Liaison Services in a General Hospital in Nepal. Nepalese Journal of Psychiatry, 1999; p. 56-62.

8. Shyangwa PM et al. Consultation-Liaison Psychiatry in General Hospital: An Experience at BPKIHS, Dharan, Nepal. Ind. J. Psych. 2002; Vol.44 Sup, 31-32.

9. Chakrabarti K. A Study of Psychiatric Referral in Patan Hospital. Souvenir of the $1^{\text {st }}$ Conference of PAN, BPKIHS, Dharan, 13-14 Nov, 1998.

10. Khalid A, Regmi SK, Koirala NR, Nepal MK and Pokharel A. Psychiatric Emergencies in a General hospital setting. Paper presented in $2^{\text {nd }}$ conference of PAN, Kathmandu, 13-14 Nov, 1999.

11. World Health Organization. The ICD-10 Classification of Mental and Behavioral Disorders Diagnostic Criteria for Research. WHO. Geneva. 1993.

12. Jhingan HP, Sharma A, Koirala $S$, Shyangwa $P$, 
Upadhyay M, Prasad KMR and Khandelwal S.K. Prevalence of alcohol dependence in a town in Nepal as assessed by CAGE questionnaire. Addiction, 1998; 339-43.

13. Slaby AE, Dubin WR, Baron DA. Other Psychiatric Emergencies. In: Sadock BJ and Sadock VA. Comprehensive Textbook of Psychiatry. $8^{\text {th }}$ edition.
Lippincott Williams and Wilkins. Philadelphia.2005. Page 2453- 71.

14. Sudak HS. Suicide. In: Sadock BJ and Sadock VA. Comprehensive Textbook of Psychiatry. $8^{\text {th }}$ edition. Lippincott Williams and Wilkins. Philadelphia. 2005. Page 2442- 52. 